\title{
Damage to ram spermatozoa by peroxidation of endogenous phospholipids
}

\author{
R. Jones and T. Mann \\ A.R.C. Unit of Reproductive Physiology and Biochemistry, \\ University of Cambridge, U.K.*
}

\begin{abstract}
Summary. We examined the damaging effects on spermatozoa of endogenous phospholipid peroxidation brought about by aerobic incubation at $37^{\circ} \mathrm{Cin}$ the presence of $0.5 \mathrm{~mm}$-ascorbic acid and $0.5 \mathrm{mM}^{-\mathrm{FeSO}_{4}}$. As well as becoming immotile, such peroxidized spermatozoa also lost, through leakage, certain intracellular enzymes into the surrounding medium, on a scale resembling that produced by cold shocking nonperoxidized spermatozoa. Morphological observations revealed that peroxidation damaged the plasma membrane, particularly in the region of the acrosome. Further experiments showed that lipid peroxidation irreversibly abolished the fructolytic and respiratory activity of spermatozoa. The susceptibility of spermatozoa to peroxidation was greater when the cells were damaged before incubation with ascorbic acid and $\mathrm{FeSO}_{4}$. To some extent, peroxidation could be prevented, but not reversed, by the addition to sperm suspensions of dialysed egg yolk or dialysed bull seminal plasma. However, dialysed seminal plasma from ram, stallion or man had no protective effect.
\end{abstract}

\section{Introduction}

The occurrence of lipofuscin granules or 'age pigments' in cells and tissues has long been attributed to the accumulation of oxidation products of unsaturated lipids (Casselman, 1951; Strehler, Mark, Mildvan \& Gee, 1959; Reichel, 1968; Porta \& Hartroft, 1969). These oxidation products have been identified as organic peroxides; they are produced in a complex series of chemical reactions, ultimately resulting in the destruction of the original lipids. Lipid peroxidation is an irreversible process, which has also been implicated in vitamin E deficiency (Bieri, 1964), irradiation damage (Philpot, 1963), certain stages of atherosclerosis (Perkins, Joh \& Kummerow, 1965), cellular injury due to carbon tetrachloride poisoning (Rechnagel, 1967) and chronic ingestion of alcohol (Reitz, 1975). The widespread distribution of unsaturated lipids in cell membranes, and their lability in the presence of oxygen, have prompted numerous investigations into the deleterious effects of lipid peroxidation. Haemolysis of erythrocytes (Tsen \& Collier, 1960), swelling of mitochondria (Hunter, Gebicki, Hoffstein, Weinstein \& Scott, 1963; McKnight \& Hunter, 1966), structural damage to DNA (Reiss \& Tappel, 1973), loss of membrane integrity, and inactivation of enzymes (Roubal \& Tappel, 1966; Wills, 1971) have all been ascribed to or correlated with the formation of lipid peroxides.

Spermatozoa are also susceptible to lipid peroxidation. Our previous studies have shown that the formation of peroxides in spermatozoa is accompanied by loss of phospholipid from the membrane and a rapid decline in motility (Jones \& Mann, 1973, 1976). The present communication is an extension of this work and deals with certain morphological, chemical and metabolic changes which become evident following peroxidation of the endogenous phospholipids.

\section{Materials and Methods}

Spermatozoa. Semen was collected from Suffolk rams by using an artificial vagina and was pooled, diluted with an equal volume of Krebs-Ringer solution, pH 7.0 (Mann, 1964) and centrifuged. The spermatozoa were washed once and resuspended in Ringer to a final concentration of approximately $0.5 \times 10^{9}$ cells $/ \mathrm{ml}$. Sperm density was estimated with a haemocytometer. Motility was scored on an arbitrary scale of 0 to 4 by an observer who did not know the experimental conditions at the time of assessment.

* Postal address: Animal Research Station, 307 Huntingdon Road, Cambridge CB3 0JQ, U.K. 
Chemicals. All chemicals and co-factors were of 'Analar' grade and were purchased from British Drug Houses (Poole, Dorset), Sigma Chemical Co. (London) or the Boehringer Corp. (London).

Enzyme assays. The activities of lactate dehydrogenase (LDH) and glutamic-oxaloacetic transaminase (GOT) were estimated by standard spectrophotometric procedures outlined in the Boehringer test-kit instructions. Hyaluronidase was determined by the method of Aronson \& Davidson (1967), as described by Brown (1975), and $\beta$ - $N$-acetylglucosaminidase by the procedure of Conchie, Findlay \& Levvy (1959).

Lipid analysis. Total lipids were extracted from spermatozoa by the procedure of Bligh \& Dyer (1959). They were separated into neutral lipids and phospholipids by thin-layer chromatography, and the phospholipid-bound fatty acids and aldehydes were estimated by gas-liquid chromatography (GLC), as described previously (Jones \& Mann, 1976).

Other procedures. The oxygen uptake of the spermatozoa was measured in Barcroft differential manometers at $37^{\circ} \mathrm{C}$, with $10 \% \mathrm{KOH}$ in the centre well and a shaking rate of 110 strokes $/ \mathrm{min}$; readings were taken at 10-min intervals. Fructolysis was estimated by the procedure of Mann (1964) and lactic acid by the $p$-hydroxydiphenol method of Barker \& Summerson(1941). The content of ATP in spermatozoa was determined by the method of Adam (1963). The formation of lipid peroxides was induced by adding $0.5 \mathrm{~mm}$-sodium ascorbate and $0.5 \mathrm{~mm}$-ferrous sulphate to the washed sperm suspension, and incubating the mixture in differential manometers filled with air; each manometer cup contained $3 \mathrm{ml}$, and the shaking rate was $110 \mathrm{strokes} / \mathrm{min}$. Unless otherwise stated, the incubation was carried out at $37^{\circ} \mathrm{C}$ for $1 \mathrm{~h}$. The peroxides were assayed by the thiobarbituric acid (TBA) reaction with malonaldehyde as the standard (Tappel \& Zalkin, 1959; Jones \& Mann, 1976). Total protein was assayed by the method of Hartree (1972).

Acrosomal membranes and plasma membranes were removed from spermatozoa by the procedure of Brown, Andani \& Hartree (1975) and the 'denuded' spermatozoa sonicated for 30 sec (Kerrys Ultrasonics). The sperm homogenate was then fractionated into a 'head' fraction and a 'midpiece-tail' fraction on linear sucrose density gradients (Stambaugh \& Buckley, 1969).

For morphological examination spermatozoa were stained with $10 \%$ nigrosin-eosin and the percentage of eosin-stained cells was estimated from counts of 300 spermatozoa. Acrosomal morphology was assessed after staining in a solution of Giemsa stain (1 volume Giemsa (Gurr) + 1 volume Sorensen's phosphate buffer, pH 7·2 12 volumes distilled water; Srivastava, 1965).

\section{Results}

\section{Changes in the permeability of spermatozoa caused by peroxidation of endogenous phospholipids}

In preliminary experiments dealing with the effects of lipid peroxidation on the permeability of the sperm plasma membrane we depended mainly on the measurement of intracellular constituents released by the spermatozoa. For this purpose, centrifuged supernatants were prepared from the following suspensions of spermatozoa: (a) fresh, untreated, (b) incubated alone for $1 \mathrm{~h}$ at $37^{\circ} \mathrm{C}$, (c) incubated for $1 \mathrm{~h}$ in the presence of $0.5 \mathrm{~mm}$-ascorbate and $0.5 \mathrm{~mm}-\mathrm{FeSO}_{4}$, and (d) subjected to rapid cooling to $0^{\circ} \mathrm{C}$ (cold shock), and thereby rendered completely immotile. These treatments enabled us to compare the behaviour of spermatozoa immobilized by peroxidation or cold shock. From the results shown in Table 1, it can be seen that peroxidation with ascorbate and Fe has led to a considerable increase in the extracellular activity level of all the enzymes measured, and that this increase occurred on a scale comparable to that registered after cold shock.

In view of reports in the literature that certain proteins and enzymes are destroyed or inactivated as a result of direct contact with lipid peroxides (Wills, 1961, 1971), we also explored the possibility that the endogenously produced peroxides themselves exert a direct inhibitory action on the enzymes which are listed in Table 1. For this purpose we used a suspension of freshly washed spermatozoa which was sonicated for $60 \mathrm{sec}$ and centrifuged at $5000 \mathrm{~g}$ for $15 \mathrm{~min}$. The supernatant was then divided into three portions of which one was used directly, another was incubated at $37^{\circ} \mathrm{C}$ for $1 \mathrm{~h}$ without additions, and the third was incubated for $1 \mathrm{~h}$ with ascorbate and $\mathrm{Fe}$. When enzyme activities were measured, it was found that in all three portions the inhibition caused by peroxidation was not more than $10-20 \%$. 
Table 1. The concentrations of protein and TBA-reactive products, and the activity of certain enzymes in supernatants prepared from ram spermatozoa

\begin{tabular}{|c|c|c|c|c|}
\hline & \multicolumn{4}{|c|}{ Supernatants from spermatozoa that were: } \\
\hline & Fresh & $\begin{array}{l}\text { Incubated } \\
\text { alone }\end{array}$ & Peroxidized* & $\begin{array}{l}\text { Cold- } \\
\text { shocked }\end{array}$ \\
\hline Protein $(\mathrm{mg} / \mathrm{ml})$ & N.D. & N.D. & $0 \cdot 9$ & 0.9 \\
\hline TBA-reaction (nmol & 2.3 & & $77 \cdot 3$ & \\
\hline $\begin{array}{l}\text { malonaldehyde/ml) } \\
\text { LDH (units } / \mathrm{I} \text { ) }\end{array}$ & $\begin{array}{r}2 \cdot 3 \\
48 \cdot 0\end{array}$ & $\begin{array}{r}6 \cdot 2 \\
134 \cdot 0\end{array}$ & $\begin{array}{r}77 \cdot 3 \\
181 \cdot 0\end{array}$ & $\begin{array}{r}3 \cdot 3 \\
191 \cdot 0\end{array}$ \\
\hline GOT (units/l) & $15 \cdot 0$ & $21 \cdot 0$ & $126 \cdot 0$ & $63 \cdot 0$ \\
\hline Hyaluronidase (units/1) & $70 \cdot 0$ & $124 \cdot 0$ & $260 \cdot 0$ & $300 \cdot 0$ \\
\hline Acid phosphatase (units/l) & 14.9 & $21 \cdot 6$ & $56 \cdot 6$ & $59 \cdot 9$ \\
\hline $\begin{array}{l}\beta-N \text {-acetylglucosaminidase } \\
\text { (units } / 1 \text { ) }\end{array}$ & 159.8 & $226 \cdot 4$ & $346 \cdot 3$ & $274 \cdot 4$ \\
\hline
\end{tabular}

N.D. = Not detectable.

* Incubated in the presence of ascorbate and $\mathrm{FeSO}_{4}$.

The fact that the lysosomal enzymes pass into the supernatants after exposure of spermatozoa to peroxidation (Table 1) indicated damage within the acrosomal region which was confirmed by morphological examination. Incubation for $1 \mathrm{~h}$ with ascorbate and $\mathrm{FeSO}_{4}$ rendered $97 \%$ of the spermatozoa eosinophilic (Table 2), and in 55\% the acrosomes were either lost altogether or exhibited distinct signs of damage (Plate 1). Ultrastructural observations also revealed that although peroxidation led to the rupture of both the plasma membrane and the outer acrosomal membrane, signs of damage to the mitochondrial sheath and axial filament were less obvious.

Table 2. The incidence of ram spermatozoa $(\%)$ that were eosinophilic or decapitated or showed damaged acrosomes

\begin{tabular}{lrcr}
\hline & \multicolumn{3}{c}{ Spermatozoa } \\
\cline { 2 - 4 } & Fresh & $\begin{array}{c}\text { Incubated } \\
\text { alone* }\end{array}$ & Peroxidized $\dagger$ \\
\hline Eosinophilic & 19 & 49 & 97 \\
Decapitated & 0 & 4 & 1 \\
With acrosome intact & 94 & 83 & 45 \\
With acrosome damaged & 2 & 0 & 20 \\
Without acrosome & 4 & 17 & 35 \\
\hline
\end{tabular}

* For $1 \mathrm{~h}$.

t Incubated for $1 \mathrm{~h}$ with ascorbate and $\mathrm{FeSO}_{4}$.

Having demonstrated damage to the acrosomal region following peroxidation of spermatozoa with ascorbate and $\mathrm{Fe}$, we next examined the intracellular localization of the phospholipids which undergo peroxidation. As shown previously, the substrate for peroxidation in ram spermatozoa is chiefly docosahexanoic acid (Jones \& Mann, 1976), and from this it could be concluded that the extreme susceptibility of the acrosome to peroxidation may depend on the presence, in the acrosome, of docosahexanoic acid in concentrations much higher than those occurring in other parts of the sperm cell. Accordingly, we determined the distribution of phospholipid-bound fatty acids in 3 different fractions prepared from fresh ram spermatozoa, consisting of (i) plasma membranes and outer acrosomal membranes, (ii) the 'denuded' heads of spermatozoa, and (iii) midpieces and tails. From Table 3 it is evident that while there were some differences between these three fractions in the distribution of short-chain fatty acids, in each fraction docosahexanoic acid was the predominant fatty acid. 
Table 3. Percentage composition of phospholipid-bound fatty acids in three fractions from washed ram spermatozoa

\begin{tabular}{cccc}
\hline & \multicolumn{3}{c}{ Fraction } \\
\cline { 2 - 4 } Fatty acid & $\begin{array}{c}\text { Acrosomal } \\
\text { plasma } \\
\text { membrane }\end{array}$ & Heads & Midpiece-tails \\
\hline $14: 0$ & 0.9 & 1.0 & $1 \cdot 2$ \\
$16: 0$ & $15 \cdot 8$ & $7 \cdot 4$ & $4 \cdot 7$ \\
$17: 0$ & Trace & Trace & Trace \\
$18: 0$ & $8 \cdot 2$ & 3.8 & $7 \cdot 2$ \\
$18: 1$ & $3 \cdot 7$ & 1.5 & $3 \cdot 0$ \\
$18: 2$ & 0.9 & - & - \\
$18: 3$ & Trace & - & Trace \\
$20: 0$ & 0.2 & - & $0 \cdot 2$ \\
$20: 4$ & 2.4 & 1.8 & 8.4 \\
$22: 6$ & $67 \cdot 8$ & 84.5 & 73.1 \\
\hline
\end{tabular}

For details of fractionation and analytical procedures see 'Materials and Methods'.

\section{Effect of lipid peroxidation on the metabolism of spermatozoa}

In an earlier study (Jones \& Mann, 1976) we reported that after spermatozoa had been incubated for $1 \mathrm{~h}$ at $37^{\circ} \mathrm{C}$ in the presence of ascorbic acid and $\mathrm{FeSO}_{4}$ they became immotile; despite this, however, the rate of oxygen uptake was not significantly different from that of control samples containing normal spermatozoa. As an explanation for this observation we suggested that any decline in the respiratory activity of peroxidized spermatozoa was compensated by oxygen being taken up in the course of the chemical process of peroxide formation. In the present study we examined more closely the long-term effects of peroxidation on the metabolism of spermatozoa and measured not only the oxygen uptake, but also fructolysis and lactate utilization. Although the oxygen uptake of washed spermatozoa incubated with ascorbate and $\mathrm{FeSO}_{4}$ did not differ significantly from that of the control after $2 \mathrm{~h}$ (Text-fig. 1a), it declined during the 3rd hour and had ceased altogether by the end of the 3-h period. However, in the presence of exogenous substrate, i.e. fructose or lactate (Text-figs $1 \mathrm{~b}$ and 1c), there was a small difference between peroxidized and normal spermatozoa which was noticeable as early as after $1 \mathrm{~h}$ of incubation; after $2 \mathrm{~h}$ the oxygen uptake of the peroxidized spermatozoa had either been arrested completely (with fructose as substrate) or reduced to a very low level (with lactate as substrate). Irrespective of the presence or absence of exogenous substrate, spermatozoa incubated with ascorbate and $\mathrm{Fe}$ were rendered immotile after $1 \mathrm{~h}$ and, moreover, gave an intense TBA reaction.

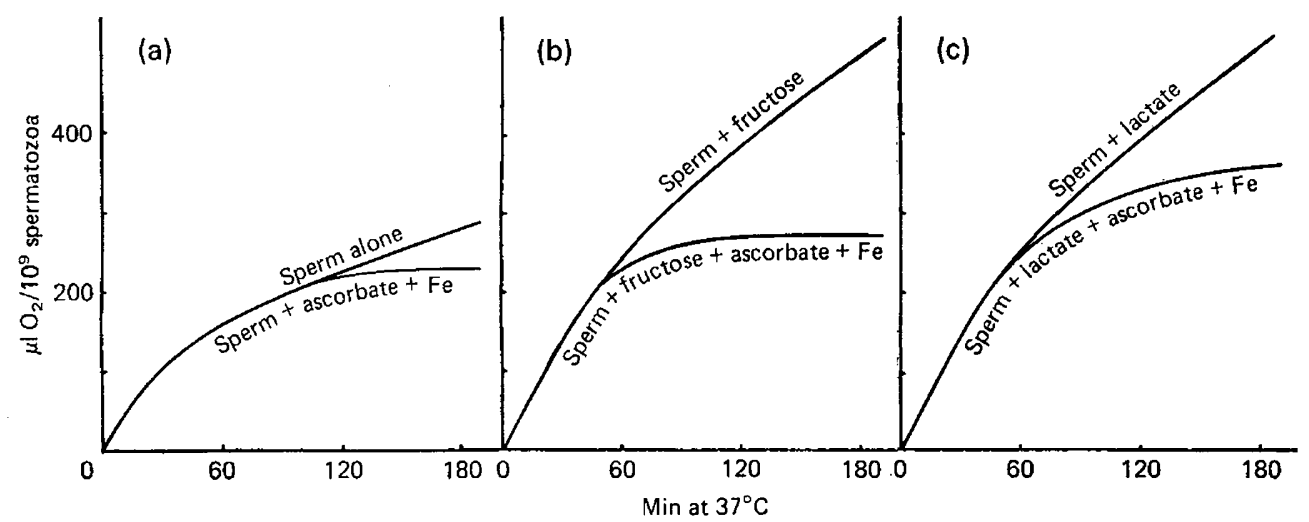

Text-fig. 1. Effect of lipid peroxidation on the oxygen uptake of a suspension of $10^{9}$ washed ram spermatozoa incubated (a) alone, (b) with $20 \mu \mathrm{mol}$ fructose, and (c) with $20 \mu \mathrm{mol}$ lithium lactate. 
PLATE 1
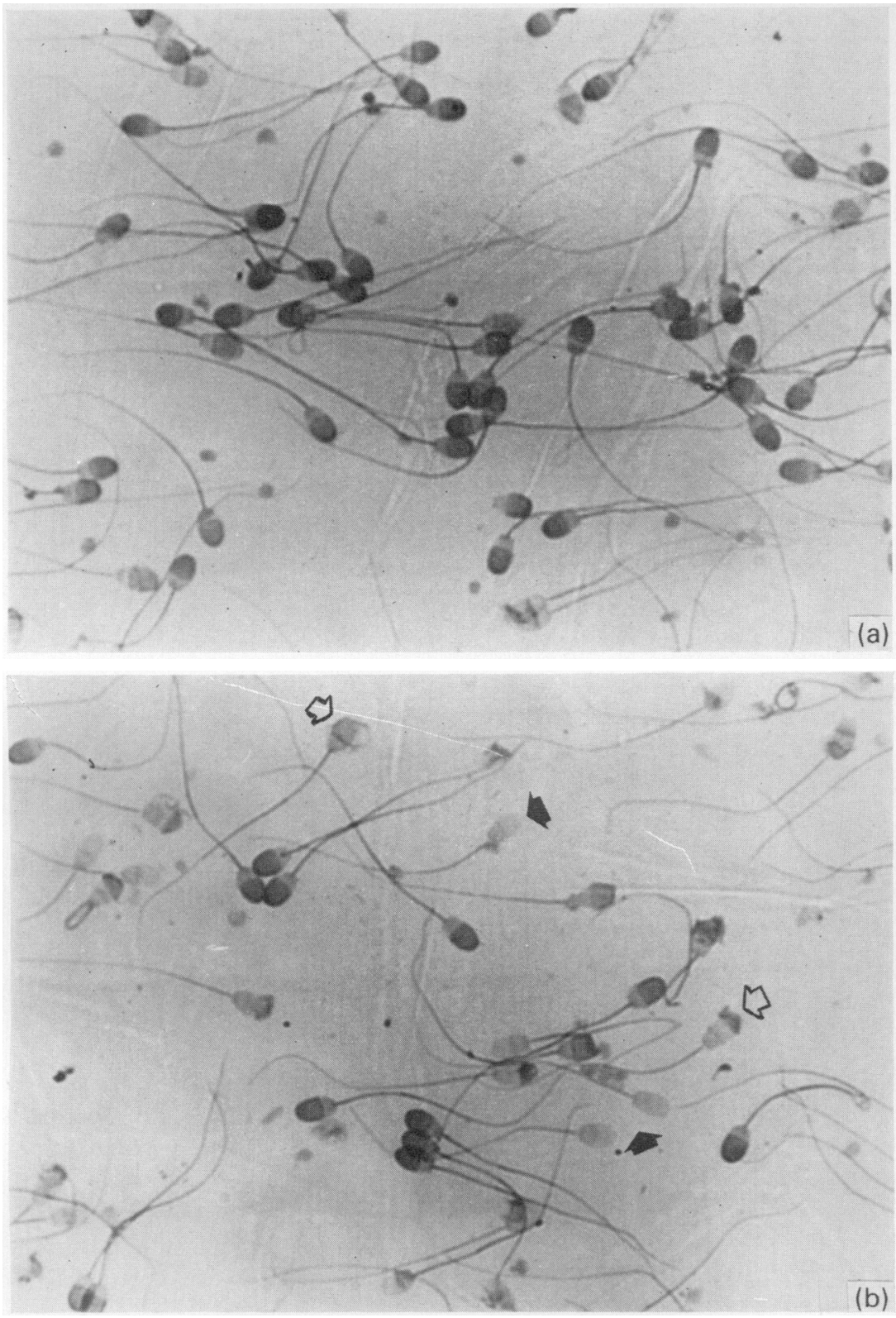

Ram spermatozoa stained with Giemsa solution after (a) aerobic incubation for $1 \mathrm{~h}$ at $37^{\circ} \mathrm{C}$ (no additions), (b) aerobic incubation for $1 \mathrm{~h}$ at $37^{\circ} \mathrm{C}$ in the presence of $0.5 \mathrm{~mm}$-ascorbic acid and $0.5 \mathrm{~mm}-\mathrm{FeSO}_{4}$. Note that in (a) nearly all spermatozoa possess an intact acrosome, whereas in (b) many spermatozoa have either lost their acrosomes completely (solid arrows) or show damage to the acrosomal region (open arrows). 


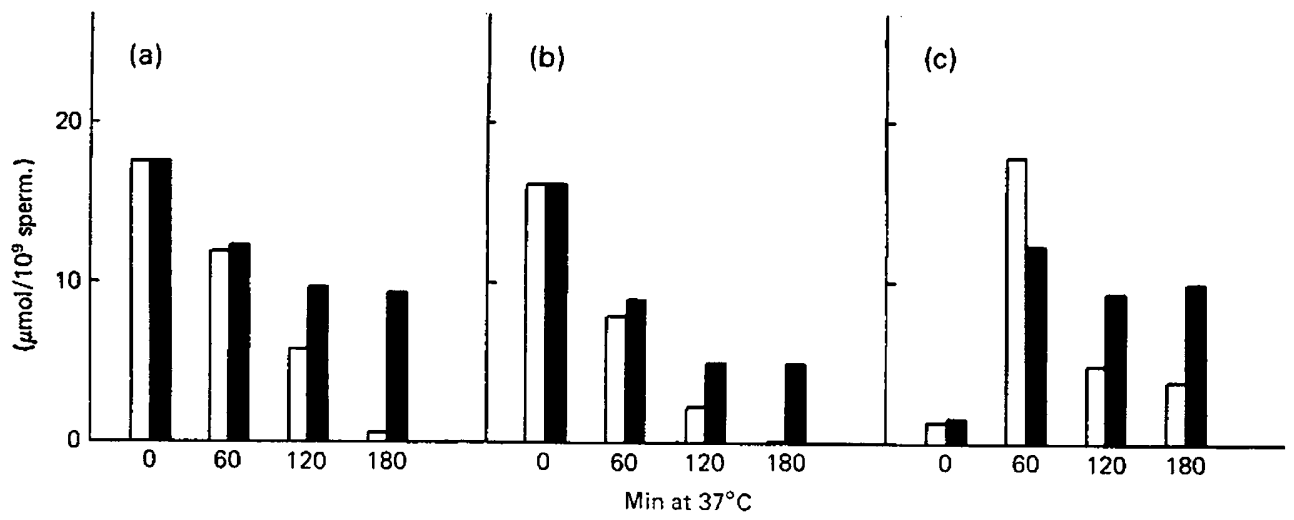

Text-fig. 2. Effect of lipid peroxidation on (a) utilization of added fructose, (b) utilization of added lithium lactate, and (c) formation of lactic acid from added fructose, by a suspension of $10^{9}$ washed ram spermatozoa. Open columns, untreated; solid columns, treated with ascorbate and $\mathrm{FeSO}_{4}$.

Pursuing this line of investigation, we determined in three further experiments with suspensions of washed ram spermatozoa the effect of lipid peroxidation on the aerobic utilization of added fructose (Text-fig. 2a), utilization of added lactate (Text-fig. 2b), and formation of lactic acid from added fructose (Text-fig. 2c). During the 1 st hour of aerobic incubation at $37^{\circ} \mathrm{C}$ the same amount of added substrate disappeared from the control and peroxidized suspension of spermatozoa, but from then onwards the metabolic activity of the peroxidized spermatozoa declined rapidly, and ceased altogether by the end of the 2 nd hour. During the 1st hour of aerobic incubation of a fructose-supplemented suspension of spermatozoa, more lactic acid accumulated in the normal than the peroxidized sample, but when incubation was extended this trend was reversed and the control suspension contained much less lactic acid than the peroxidized sample, presumably because of the progressively increasing lactate oxidation by the normal, as distinct from peroxidized, spermatozoa.

Table. 4. Effect of peroxidation on the ATP content (nmol/109 spermatozoa) and motility index (in parentheses) of washed ram spermatozoa incubated at $37^{\circ} \mathrm{C}$ in media containing no substrate, $10 \mathrm{~mm}$ fructose or $10 \mathrm{~mm}$ lactate

\begin{tabular}{lcrrr}
\hline \multirow{2}{*}{ Addition to medium } & \multicolumn{4}{c}{ ATP and motility } \\
\cline { 2 - 5 } & $0 \mathrm{~min}$ & $60 \mathrm{~min}$ & $120 \mathrm{~min}$ & $180 \mathrm{~min}$ \\
\hline None & $346(3)$ & $152(2)$ & $160(2)$ & $154(2)$ \\
Ascorbate + Fe & $276(3)$ & $56(0)$ & $28(0)$ & $44(0)$ \\
Fructose & $346(4)$ & $346(3)$ & $340(3)$ & $324(3)$ \\
Fructose + ascorbate + Fe & $304(3)$ & $152(0)$ & $72(0)$ & $36(0)$ \\
Lactate & $382(3)$ & $276(3)$ & $308(3)$ & $142(2)$ \\
Lactate + ascorbate + Fe & $238(3)$ & $36(0)$ & $48(0)$ & $56(0)$ \\
\hline
\end{tabular}

Coincidental with the loss of motility due to peroxidation, there was a rapid fall in the level of ATP in spermatozoa (Table 4).

\section{Enhanced susceptibility to peroxidation of previously damaged spermatozoa}

Like ageing, some other forms of cellular damage enhance the rate of peroxidation in certain tissues. Because spermatozoa are invariably exposed to a considerable amount of manipulation and stress during the collection and storage of semen, an investigation was made of the effect of cellular damage, particularly from cold shock, on the rate at which peroxidation changes occur in spermatozoa. The rate of peroxidation in the suspension of washed ram spermatozoa was approximately doubled if, before the addition of ascorbate and $\mathrm{FeSO}_{4}$, the spermatozoa were damaged by cold shock or by aerobic preincubation for $4 \mathrm{~h}$ at $37^{\circ} \mathrm{C}$ (Text-fig. 3). Moreover, the peroxidation proceeded in the 


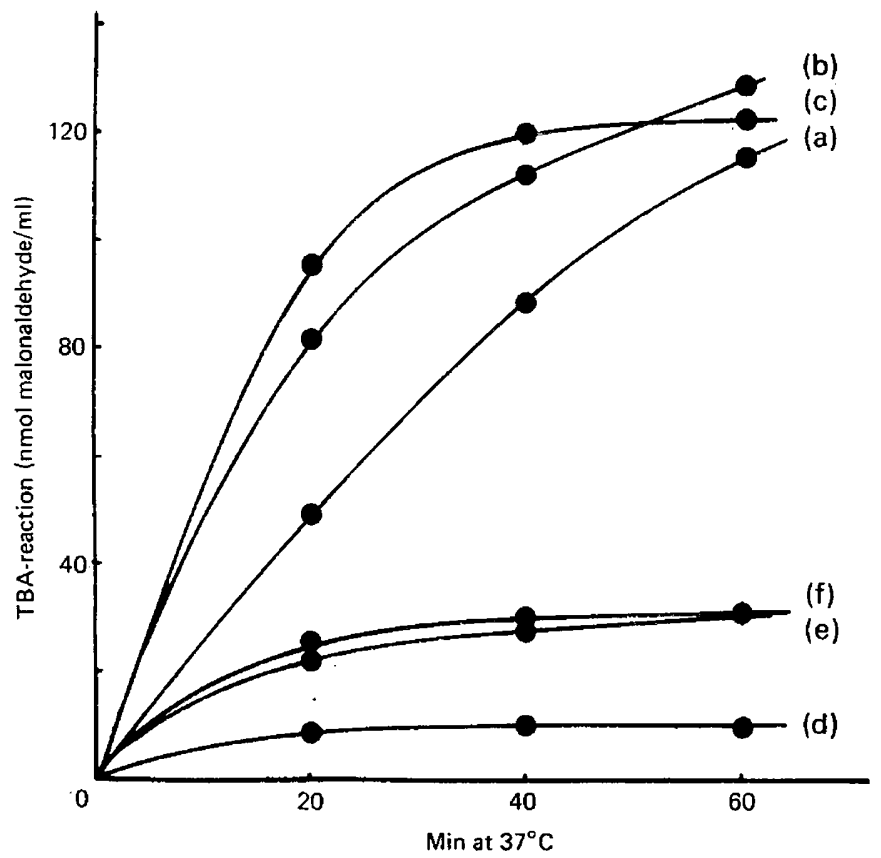

Text-fig. 3. Development of the thiobarbituric acid (TBA) reaction in the presence of ascorbate and $\mathrm{FeSO}_{4}$, determined after 20,40 and 60 min incubation at $37^{\circ} \mathrm{C}$. The three upper curves $(a, b, c)$ show the progress of the reaction in whole suspensions of washed ram spermatozoa used either (a) fresh or (b) after aerobic preincubation for $4 \mathrm{~h}$ at $37^{\circ} \mathrm{C}$ or (c) after exposure to cold shock. The three lower curves (d, e, f) show the progress of peroxidation in the supernatants obtained by centrifuging the (d) fresh, (e) preincubated and (f) cold-shocked suspension.

centrifuged supernatants from the sperm suspensions at a distinctly higher rate after the spermatozoa had been damaged, indicating that there had been release of lipoprotein from the damaged spermatozoa.

\section{Effect of seminal plasma and egg-yolk diluent on the peroxidation process}

The influence of seminal plasma on the formation of lipid peroxides in washed ram spermatozoa is shown in Table 5. Dialysed seminal plasma from ram, stallion and man did not prevent peroxidation, but that from bull almost completely prevented the TBA reaction in ram spermatozoa. The reason for this species difference still remains to be explored, but in some preliminary experiments, carried out

Table 5. The effect of various additives $(1 \mathrm{ml})$ to a suspension of washed ram spermatozoa $(1 \mathrm{ml})$ at the start of incubation with ascorbate and $\mathrm{FeSO}_{4}$ on the formation of the TBA-reactive product (nmol malonaldehyde $/ 10^{9}$ spermatozoa) demonstrated at the end of a 1 -h incubation at $37^{\circ} \mathrm{C}$

Addition

Krebs-Ringer solution

Dialysed bull seminal plasma

Dialysed human seminal plasma

Dialysed ram seminal plasma

Dialysed stallion seminal plasma

Dialysed egg yolk
TBA-reactive product

124

The seminal plasma and the egg yolk were dialysed against the Krebs-Ringer solution, i.e. the medium normally used for washing the spermatozoa. 
with spermatozoa of species other than ram, we found that whereas the spermatozoa of man, boar and stallion give a strong TBA reaction in the presence of ascorbate and $\mathrm{FeSO}_{4}$, bull spermatozoa are not easily peroxidized. It is, however, known from the study of Poulos, Darin-Bennett \& White (1973) that bovine spermatozoa are rich in phospholipid-bound unsaturated fatty acids.

Egg yolk, a common constituent of semen extenders, was also found to reduce the rate of the peroxidation in ram spermatozoa, but was not as effective as bull seminal plasma.

\section{Discussion}

It is now generally recognized that molecular oxygen, particularly at high partial pressure, can be toxic not only to obligate anaerobes but to other forms of life, and that its toxicity is due primarily to the formation of certain intermediates of oxygen reduction, and in particular, to two highly reactive free radicals: the superoxide anion radical $\mathrm{O}_{2}^{-}$and the hydroxyl radical $\mathrm{OH} \cdot$. The latter, an especially potent oxidant, is capable of interacting with many organic substances at rates that are close to the theoretical limits set by diffusion (Fridovich, 1974).

Organic peroxides produced during the free radical oxidations include the highly toxic lipid peroxides which are generated during the aerobic oxidation of unsaturated lipids (Uri, 1961; Bernheim, 1963; Walling, 1963). Essentially, lipid peroxidation is an autocatalytic process which can, however, be considerably speeded up by the addition of ascorbate and catalytic amounts of certain heavy metal cations such as $\mathrm{Fe}^{2+}, \mathrm{Co}^{2+}$ or $\mathrm{Cu}^{2+}$ (Ottolenghi, 1959; Wills, 1965). These metal cations are believed to act either by initiating the formation of free radicals or by increasing the rate of breakdown of peroxides to short-chain carbon fragments, the latter including malonaldehyde, a substance which can conveniently be measured owing to the formation of a coloured reaction product with thiobarbituric acid.

The concept that 'autointoxication' can occur in spermatozoa, and that it can lead to 'senescence', was expressed by Gray $(1928,1931)$ but without identification of the nature of the toxic 'metabolites'. The formation of lipid peroxides could be at least one of the causes of both 'oxygen damage' and 'autointoxication' in spermatozoa. One of the main conclusions emerging from our studies, past and present, is that spermatozoa are highly susceptible to peroxidation of their endogenous phospholipids. The process of peroxidation is accompanied by extensive structural alterations, particularly in the acrosomal region of the sperm cell, a rapid and irreversible loss of motility, a profound change in metabolism, and a high rate of 'leakage' of intracellular sperm constituents.

At the moment, we are uncertain about the mechanism underlying toxicity of the endogenously produced lipid peroxides. The direct action of lipid peroxides on various enzymes in spermatozoa, in particular those that are membrane-bound and contain SH groups, needs to be examined more closely because lipid peroxides are known to be capable of inactivating certain $\mathrm{SH}$-containing proteins and enzymes (Lewis \& Wills, 1962).

The most plausible explanation for the prevention (but not reversal), by the dialysed bovine seminal plasma, of the strong TBA reaction given by ram spermatozoa after incubation with ascorbate and ferrous sulphate is an iron-chelating action of protein(s) in the seminal plasma. Bovine spermatozoa might be resistant to peroxidation because they acquire a 'coat' of the protective seminalplasma protein at the time of semen ejaculation.

T.M. gratefully acknowledges support from the Leverhulme Trust Fund.

\section{References}

Avam, H. (1963) Adenosine-5'-phosphate. Determination with phosphoglycerate kinase. In Methods of Enzymatic Analysis, pp. 539-543. Ed. H. U. Bergmeyer. Verlag Chemie, Academic Press, New York.

Aronson, N.N., JR \& Davidson, E.A. (1967) Lysosomal hyaluronidase from rat liver. J. biol. Chem. 242, 437440 .
Barker, S.B. \& Summerson, W.H. (1941) The colorimetric determination of lactic acid in biological material. J. biol. Chem. 138, 535-554.

BerNheIM, F. (1963) Biochemical implications of prooxidants and anti-oxidants. Radiat. Res., Suppl. 3, 17-32.

BIERI, J.G. (1964) Antioxidant effects in biochemistry and physiology. Progr. Chem. Fats Lipids 7, 247-266. 
BLIGH, B.G. \& DYER, W.J. (1959) A rapid method of total lipid extraction and purification. Canad. J. Biochem. Physiol. 37, 911-917.

Brown, C.R. (1975) Distribution of hyaluronidase in the ram spermatozoon. $J$. Reprod. Fert. 45, 537-539.

Brown, C.R., ANDANI, Z. \& Hartree, E.F. (1975) Studies on ram acrosin. Isolation from spermatozoa, activation by cations and organic solvents, and influence of cations upon its reaction with inhibitors. Biochem. J. 149, 133-146.

Casselman, W.G.B. (1951) The in vitro preparation and histochemical properties of substances resembling ceroid. J. exp. Med. 94, 549-562.

Conchie, J., Findlay, J. \& Levvy, G.A. (1959) Mammalian glycosidases. Distribution in the body. Biochem. J. 71, 318-325.

Fridovich, I. (1974) Superoxide and evolution. Horizons Biochem. Biophys. 1, 1-37.

GRAY, J. (1928) The senescence of spermatozoa. $B r . J$. exp. Biol. 5, 345-361.

GrAY, J. (1931) The senescence of spermatozoa II. J. exp. Biol. 8, 202-210.

HARTREE, E.F. (1972) Determination of protein: a modification of the Lowry method that gives a linear photometric response. Analyt. Biochem. 48, 422-427.

Hunter, F.E., JR, Gebicki, J.M., Hoffstein, P.E., Weinstein, J. \& Scott, A. (1963) Swelling and lysis of rat liver mitochondria induced by ferrous ions. J. biol. Chem. 238, 828-835.

Jones, R. \& MANN, T. (1973) Lipid peroxidation in spermatozoa. Proc. $R$. Soc. B 184, 103-107.

JONES, R. \& MANN, T. (1976) Lipid peroxides in spermatozoa; formation, rôle of plasmalogen and physiological significance. Proc. R. Soc. B 193, 317-333.

LEWIS, S.E. \& WiLls, E.D. (1962) The destruction of -SH groups of proteins and amino acids by peroxides of unsaturated fatty acids. Biochem. Pharmacol. 11, 901-912.

MANN, T. (1964) The Biochemistry of Semen and of the Male Reproductive Tract. Methuen, London.

MCKNIGHT, R.C. \& Hunter, F.E., JR (1966) Mitochondrial membrane ghosts produced by lipid peroxidation induced by ferrous ion. J. biol. Chem. 241, 2757-2765.

OTTOLENGHI, A. (1959) Interaction of ascorbic acid and mitochondrial lipides. Archs Biochem. Biophys. 79, 355-363.

Perkins, E.G., Joh, T.H. \& Kummerow, F.A. (1965) The composition of the extractable and bound lipids of the human aorta. In Metabolism of Lipids as Related to Atherosclerosis, pp. 48-61. Ed. F. A. Kummerow. C. Thomas, Springfield.

Philpot, J. St. L. (1963) The estimation and identification of organic peroxides. Radiat. Res., Suppl. 3, 5570 .
Porta, E.A. \& HarTrofT, W.S. (1969) Lipid pigments in relation to aging and dietary factors (lipofuscins). In Pigments in Pathology, pp. 191-235. Ed. M. Wolman. Academic Press, New York.

Poulos, A., Darin-BenNet, A. \& White, I.G. (1973) The phospholipid-bound fatty acids and aldehydes of mammalian spermatozoa. Comp. Biochem. Physiol. 46B, 541-549.

RECHNAGEL, R.O. (1967) Carbon tetrachloride hepatotoxicity. Pharmacol. Rev. 19, 145-208.

ReICHEL, W. (1968) Lipofuscin pigment accumulation and distribution in five rat organs as a function of age. J. Gerontol. 23, 145-153.

ReISS, U. \& TAPPEL, A.L. (1973) Fluorescent product formation and changes in structure of DNA reacted with peroxidising arachidonic acid. Lipids 8, 199-202.

ReITZ, R.C. (1975) A possible mechanism for the peroxidation of lipids due to chronic ethanol inges. tion. Biochim. biophys. Acta 380, 145-154.

Roubal, W.T. \& TAPPEL, A.L. (1966) Damage to proteins, enzymes and amino acids by peroxidising lipids. Archs Biochem. Biophys. 113, 5-8.

SRIVAstava, P.N. (1965) Biochemistry of the spermacrosome with special reference to sialic acid. Ph.D. thesis, University of Cambridge.

Stambaugh, R. \& Buckley, J. (1969) Identification and subcellular localization of the enzymes effecting penetration of the zona pellucida by rabbit spermatozoa. J. Reprod. Fert. 19, 423-432.

Strehler, B.L., Mark, D.D., Mildvan, A.S. \& Gee, M.V. (1959) Rate and magnitude of age pigment accumulation in the human myocardium. J. Gerontol. 14, 430-439.

TAPPEL, A.L. \& ZALKIN, H. (1959) Lipid peroxidation in isolated mitochondria. Archs Biochem. Biophys. 80, 326-332.

TSEN, C.C. \& Collier, H.B. (1960) The protective action of tocopherol against hemolysis of rat erythrocytes by dialuric acid. Canad.J. Biochem. Physiol. 38, 957-964.

URI, N. (1961) Physico-chemical aspects of autoxidation. In Autoxidation and Antioxidants, Vol. I, pp. 55-106. Ed. W.O. Lundberg. John Wiley \& Sons, New York.

Walling, C. (1963) Chemistry of the organic peroxides. Radiat. Res., Suppl. 3, 3-16.

WiLLs, E.D. (1961) Effect of unsaturated fatty acids and their peroxides on enzymes. Biochem. Pharmacol. 7, 7-16.

WiLls, E.D. (1965) Mechanisms of lipid peroxide formation in tissues. Role of metals and haematin proteins in the catalysis of the oxidation of unsaturated fatty acids. Biochim. biophys. Acta 98, 238-251.

Wills, E.D. (1971) Effects of lipid peroxidation on membrane-bound enzymes of the endoplasmic reticulum. Biochem. J. 123, 983-991.

Received 22 October 1976 